\title{
THE SIGNIFICANCE OF AUDITORY STUDY TO BLIND UNIVERSITY STUDENTS
}

Pol GHESQUIÈRE, Jan LAURIJSSEN, Wied RUIJSSENAARS \& Patrick ONGHENA

Mailing adress

University of Leuven Faculty of Psychology and Educational Sciences Department of Special Education

Vesaliusstraat 2

B-3000 Leuven

Belgium

tel.: ++ 3216326234

fax.: ++ 3216325933

pol.ghesquiere@ped.kuleuven.ac.be 


\section{Introduction}

A considerable amount of research has been carried out into study skills and strategies of university students. Not much attention has been paid, however, to students with a visual handicap. In this area, two studies are extremely relevant. Bishop (1986) found that variables relating to school performance are considered very important for achieving an independent life. Erin, Corn and Wolffe (1993) concluded that with regard to learning and study skills there are no great differences between students with a visual handicap and students with normal vision. Their conclusion that blind persons compensate for their visual handicap raises the question whether auditory studying might well be very important to them. This question will be investigated in this contribution.

\section{Auditory compensation}

The question whether blind people have a better hearing has been often investigated and mostly was answered affirmatively. It was explained by the hypothesis that blind people compensate for the loss of visual facilities. This explanation comes in two forms. The auditory compensation may consist of a reorganization and re-allocation at the level of the cortex, so that tactile and auditory areas are functioning better (structural compensation hypothesis). It is also possible, however, that as a result of the visual handicap, tactile and auditory skills develop better (strategic compensation hypothesis) (Miller, 1992).

Research results in this area are contradictory. Starlinger and Niemeyer (1981) confirm the structural compensation hypothesis, whereas Hollins (1989) illustrates the strategic compensation hypothesis with research into echo location, the ability to perceive and avoid obstacles by processing information reflected by echo or sound. 
A number of factors may be relevant to the performance of blind persons. The age at which the handicap originated might affect the development of compensatory auditory skills, or the central functions of the auditory system (Miller, 1992). How long the handicap has existed, is considered to be a factor in compensation as well. A third factor is related to the degree or the seriousness of the handicap.

The question what precisely makes blind subjects perform better on a number of auditory tasks has not yet been answered unequivocally.

\section{Study problems of blind students}

At the counseling of handicapped students at the Leuven University it was noticed that blind students used various study methods: tactile, auditory, or a mixture of the two. Tactile processing of information is an obvious choice, as blind persons have been trained in school to process information by reading Braille mainly. Apparently, however, a number of students discard this method and switch completely or partially to an auditory method. In a lot of cases, this is a consequence of the fact that information access in postsecondary education is mostly realised with audiotapes (Senge \& Dote-Kwan, 1995). This observation sparked off the present investigation.

Auditory studying means information processing mainly by ear. Hearing is the medium for information input -- what does this mean for a blind university student?

The availability of information is the first step in the study process. This implies, among other things, that the student should have the material (course text) on tape in time. In addition, the student should 
also have lecture notes; to this end, the student may tape lectures or summarize them afterwards on tape.

Next, the information should be studied, edited and archived. All of the subject matter has to be listened to; after that, the student may make a summary or outline. Students who use auditory processing employ several tape decks in order to be able to listen to everything.

This method has its drawbacks. Courses are not available in time; it is difficult to get an overview of the course; students have difficulties in retrieving something quickly for a review. Auditory studying is very time-consuming and not all material, for example drawings and charts, can be put into verbal form. Processing study material through Braille, however, has the same drawbacks (Van Overbeke, 1992).

What, then, may be the relevance of auditory studying? "A study method aims at an evolution from a thorough understanding of the essentials and the main links, to a good knowledge of the details." (Van Acker, 1990, p. 2). However, a visual or spatial image of the subject is not necessary for a structured image or good understanding of the matter. Understanding the subject is not exclusively linked to a specific mode of perception. Structuring is a mental, cognitive process which may be induced by senses other than the purely visual (Van Acker, 1990). The emphasis on visual or tactile processing of information is a result of the general didactic emphasis on these processing modes. Apparently, little attention is given to auditory studying, when both blind and sighted students are being educated. We have not, however, found any proof indicating that auditory studying is a less good or less effective way of studying. Auditory study is a cumbersome process for blind students, but the difficulties associated with it are comparable to the problems related to studying through Braille (Van Overbeke, 1992). 


\section{A pilot study}

This study raises two research questions: 1) to what extent is auditory study relevant for blind students, when compared to tactile study, and 2) are blind students doing better at auditory study than normally sighted students.

\section{Subjects}

The subjects were 6 sighted and 6 blind university students. The criteria for inclusion in the 'blind' group were total blindness, mastering Braille, and enrollment in or a degree of a university course of study; partially sighted students were not included in the project. This experimental group consisted of four women and two men, aged between 19 and 23 years (average age 21.5 years). The number of subjects is small because the target group of blind students at the Leuven University is extremely small. The following criteria were adopted for the 'sighted' group: normal eyesight, and enrollment in a university course. The two groups were not matched. The sighted students were volunteers from the same faculties of the blind students. This group consisted of six men aged between 20 and 22 years (average age 21 years).

\section{Instrument}

The Logical-Verbal Learning test (L.V.L.) developed by Magez (1982) was used. This test aims at creating an experimental learning situation in which the students' learning attitudes and abilities are tested by means of logical-verbal material (a text). The students are given a three-page text (The 
The significance of auditory study to blind university students 6

behavior of animals) which they have to study for 20 minutes. They are allowed to make notes. After the study period they are asked to answer questions about the structure of the text ( ; $\max =44)$, its contents $(C$; $\max =36)$ and definitions of terms discussed in the text $(\mathrm{D}$; max=24). The answering time is 20 minutes. Depending on the experimental condition, the L.V.L. was taken from the blind students either tactile or auditory, and from the sighted students either visually or auditory.

\section{Research design}

The L.V.L. was taken twice with an interval of two weeks, but in different ways. This made it possible to monitor the learning effect of repeated testing, and to investigate wether there is a difference in learning effect depending on the order of presentation. A 'counterbalancing design' was choosen, in which all subjects pass the various conditions (Campbell \& Stanley, 1963). In this way, both inter and intra-group comparisons are possible. Hence, the entire experimental group may be divided into four subgroups:

group 1: 3 sighted students, first presentation visual, second auditory (V-A) group 2: 3 sighted students, first presentation auditory, second visual (A-V) group 3: 3 blind students, first presentation tactile, second auditory (T-A) group 4: 3 blind students, first presentation auditory, second tactile (A-T)

\section{Results}

On the basis of the correlations between subjects' performances in the various conditions of the test (table 1), we see that the Logical-Verbal Learning test is a relatively coherent test. 


\begin{tabular}{|l|lllllll|}
\hline & S1 & C1 & D1 & Tot1 & S2 & C2 & D2 \\
\hline C1 & .44 & & & & & & \\
D1 & $.81^{\star \star}$ & .54 & & & & & \\
Tot1 & $.92^{\star \star}$ & $.73^{\star \star}$ & $.90^{\star \star}$ & & & & \\
S2 & $.77^{\star \star}$ & $.63^{\star}$ & $.62^{\star}$ & $.81^{\star \star}$ & & & \\
C2 & $.62^{\star}$ & $.83^{\star \star}$ & $.71^{\star \star}$ & $.82^{\star \star}$ & $.81^{\star \star}$ & & \\
D2 & $.79^{\star \star}$ & .51 & $.85^{\star \star}$ & $.83^{\star \star}$ & $.66^{\star}$ & $.76^{\star \star}$ & \\
Tot2 & $.78^{\star \star}$ & $.73^{\star \star}$ & $.75^{\star \star}$ & $.88^{\star \star}$ & $.95^{\star \star}$ & $.94^{\star \star}$ & $.81^{\star \star}$ \\
\hline
\end{tabular}

Table 1: Correlations between the scores on the L.V.L. (entire group)

Table 2 shows the average scores and standard deviations on the L.V.L. of the four subgroups.

\begin{tabular}{|l|ll|ll|}
\hline Group & Tot1 & sd1 & Tot2 & sd2 \\
\hline V - A & $\mathbf{7 1 . 0}$ & 7.9 & $\mathbf{7 8 . 3}$ & 4.6 \\
A - V & $\mathbf{5 2 . 3}$ & 7.1 & $\mathbf{6 9 . 3}$ & 8.1 \\
T - A & $\mathbf{2 6 . 0}$ & 16.6 & $\mathbf{4 9 . 0}$ & 16.5 \\
A - T & $\mathbf{5 4 . 7}$ & 13.8 & $\mathbf{7 7 . 7}$ & 22.4 \\
\hline Total & $\mathbf{5 1 . 0}$ & 19.7 & $\mathbf{6 8 . 6}$ & 17.6 \\
\hline
\end{tabular}

Table 2: Averages and standard deviations on the scores on the L.V.L. per subgroup

By means of a repeated measures ANOVA we conclude that there is a main effect on group, $F(3,8)=4.58, p=.03778^{*}$, and on time, $F(1,8)=65.86, p=.00005^{*}$. There is no interaction effect, $F(3,8)=2.91, p=.098447^{*}$.

In answer to the first research questions, we find that the overall average of the blind students in the auditory condition is equal to their overall average in the tactile condition ( $x=51.833)$. Notice, however, the large variance in the performances of the blind students, especially in the tactile condition.

In answer to the second research question, we may not conclude that blind students do better at auditory study than normally sighted students, $F(1,8)=4.096, p=.0778^{* *}$. There is no question of a better auditory result. 
Figure 1 offers a graphical representation of the average total score for the four subgroups in the experiment (taking into account the condition and order of presentation). A number of distinctive trends can be observed in the results.

\section{[ insert figure 1 here ]}

In the sighted group, those subjects studying visually on the first presentation score higher than those following the auditory method. When the subjects take the test a second time, the visual study method gives the original auditory group the opportunity to recover lost ground. Although this may be due to a ceiling effect, visual studying appears to be the most efficient strategy for sighted students, a conclusion which might have been confirmed by the results of a V-V group.

With the blind group, we notice that on the first presentation better results are scored in the auditory situation than in the tactile situation. When the presentation mode changes, however, the difference remains the same. Apparently auditory study is important for blind persons, in any case as an opening strategy. It would be interesting to have the results from a blind group in an A-A situation.

It is remarkable that on the first presentation the blind A-T group performs equally well as the sighted A-V group. This confirms that there is no question of a better auditory result. The blind A-T group's performance equals that of the sighted V-A group on the second presentation. The absence of the visual method apparently is a certain handicap when studying texts. This again emphasizes the importance of a visual strategy for sighted people.

\footnotetext{
* Because the samples were so small, the p-value was estimated with a Monte Carlo permutation procedure based on 100,000 permutations (May, Hunter \& Masson, 1993).

** This p-value was estimated with an exhaustive permutation procedure (369,600 permutations).
} 


\section{Discussion}

Barraga (1976) offered the following proposition: “As visually handicapped youth reach junior and senior high school, reliance on listening as primary means of learning reaches its peak; any future pursuit in higher education will require almost total reliance on listening for learning” (p. 52). Even though our exploratory investigation cannot offer any concrete support for this view, we may conclude that auditory learning is an important study strategy for blind university students. In the sighted group we found the reverse effect. In reality, however, there is a one-sided emphasis in education on tactile processing of study material (Van Acker, 1990). Even though the auditory strategy might not be the only method for every student, we can demonstrate on the basis of our investigation that, for some students, this may be a more effective method of study. Further research into the possibilities and limitations of auditory study and its integration into education is obviously required. Moreover, it is necessary to find pointers which will enable us to detect the blind students' preferred strategy. This could then provide stratagems on which counseling could be based, and to which the educational system would have to adapt.

\section{Literature}

Barraga, N. (1976). Visual Handicaps and Learning: a Developmental Approach. Belmont: Wordsworth.

Bishop, V.E. (1986). Identifying the Components of Success in Mainstreaming. Journal of Visual Impairment and Blindness, 80, 939-946.

Campbell, D.T. \& Stanley, J.C. (1963). Experimental and Quasi-experimental Designs for Research. Chicago (Ill.): Rand MacNally.

Erin, J.N., Corn, A.L. \& Wolffe, K. (1993). Learning and Study Strategies of Secondary School Students with Visual Impairments. Journal of Visual Impairment and Blindness, 87, 263-267. 
The significance of auditory study to blind university students 10

Hollins, M. (1989). Understanding Blindness: an Integrative Approach. Hillsdale: Erlbaum.

Magez, W. (1982). Logisch Verbale Leerproef (L.V.L.) Voor Einde Hoger Secundair Onderwijs. Brussel: C.S.B.O.

May, R., Hunter, M. \& Masson, M. (1993). NP-Stat 3.7. Victoria, B.C. (Canada): University of Victoria, Department of Psychology.

Miller, L. (1992). Diderot Reconsidered: Visual Impairment and Auditory Compensation. Journal of Visual Impairment and Blindness, 86, 206-210.

Senge, J.C. \& Dote-Kwan, J. (1995). Information Accessibility in Alternative Formats in Postsecondary Education. Journal of Visual Impairment \& Blindness, 89 (2), 120-128.

Starlinger, I. \& Niemeyer, W. (1981). Do the Blind Hear Better? Investigations on Auditory Processing in Congenital or Early Acquired Blindness. I. Peripheral Functions. Audiology, 20, 503-509.

Starlinger, I. \& Niemeyer, W. (1981). Do the Blind Hear Better? Investigations on Auditory Processing in Congenital or Early Acquired Blindness. II. Central Functions. Audiology, 20, 510-515.

Van Acker, M. (1990). Tradition, Experience, Current Status and Prospects of Visually Handicapped Students.

Unpublished manuscript. Center for Handicapped Students, Leuven University.

Van Acker, M. (1990). Counseling Assessment, Advisory Services, Student Selection Methods, Teaching Support, Examination and Vocational Integration of Visually Handicapped University Students. Unpublished manuscript. Center for Handicapped Students, Leuven University.

Van Overbeke, M. (1992). Exploratief Onderzoek naar de Studiemethode van Braillisten in het Hoger Onderwijs in Vlaanderen. Unpublished thesis. Faculty of Psychological and Pedagogical Sciences, U. Gent.

Pol Ghesquière, Ph.D., professor of special education, Katholieke Universiteit Leuven (Belgium); Jan Laurijssen, M. Ed. Sc., schoolcounselor, school guidance centre Vilvoorde (Belgium); Wied Ruijssenaars, Ph.D., professor of special education, Leiden University (the Netherlands); Patrick Onghena, Ph.D., professor of methods and statistics in educational sciences, Katholieke Universiteit Leuven (Belgium) 
Fig. 1: Scores of the subgroups

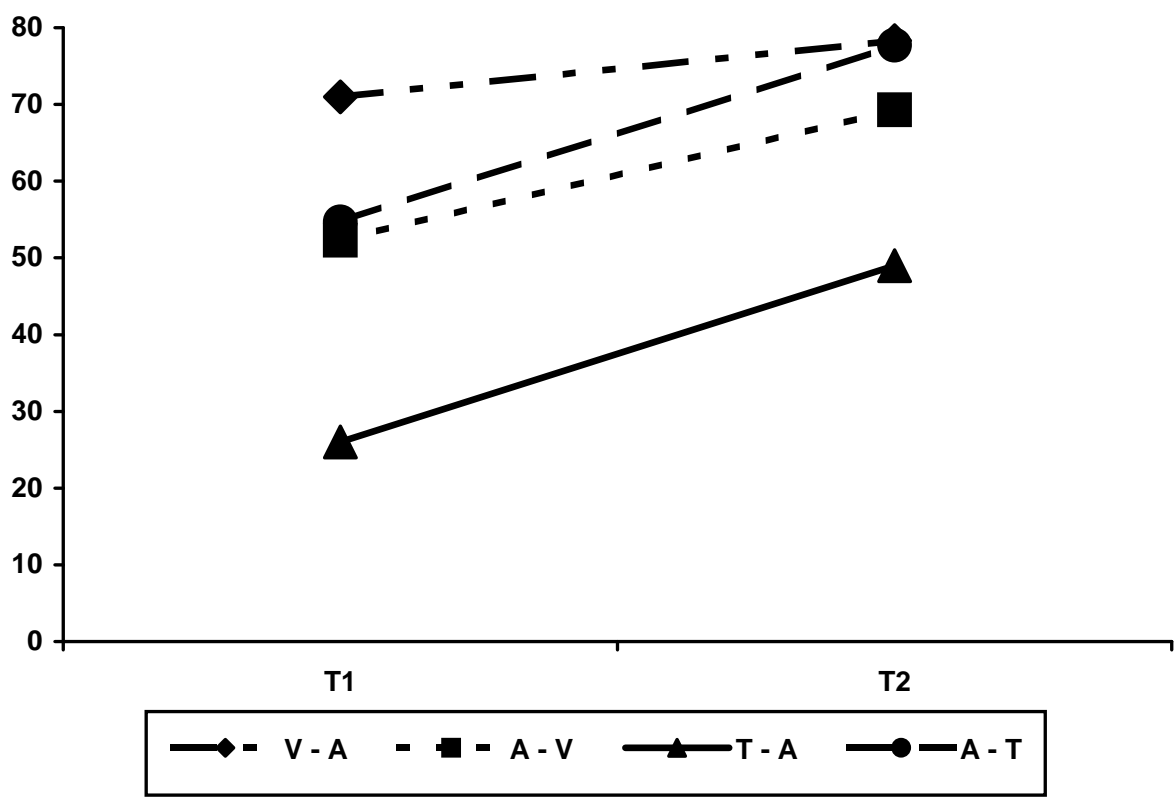




\section{Abstract}

The subjects in the study described, 6 blind and 6 fully sighted university students, were tested twice (either visual/tactile or auditory) with a logical-verbal learning test. The overall averages of the blind students were equal in the auditory and tactile conditions and they did not better at auditory study than did the fully sighted students. Visual study appears to be the most efficient strategy for sighted students. Auditory study seems important for persons who are blind. 